\title{
A recepção da Teoria Crítica no Brasil: 1968-1978
}

\section{The reception of Critical Theory in Brazil: 1968-1978}

\author{
Sílvio César Camargo \\ Doutor em Sociologia pela Universidade Estadual de Campinas (UNICAMP) \\ Professor no Departamento de Sociologia/IFCH - UNICAMP \\ silviocc@terra.com.br
}

\begin{abstract}
Resumo:
Nosso propósito nesse artigo é refletir sobre o que consideramos ser a primeira fase do processo de recepção da Teoria Crítica da Escola de Frankfurt no Brasil com ênfase na produção de alguns intelectuais brasileiros que foram pioneiros nesse processo, não apenas como tradutores e divulgadores do pensamento frankfurtiano, mas também como intérpretes da realidade nacional. Em um período histórico conturbado, marcado pela repressão do regime militar, intelectuais como José G. Merquior, Roberto Schwarz, Gabriel Cohn e Flávio Kothe, em diferenciadas nuanças teóricas, principiaram a recepção da teoria crítica no Brasil, sua imersão nas Ciências Sociais do país e com repercussões quanto à própria forma de compreensão da sociedade brasileira.
\end{abstract}

Palavras-chave: Teoria social. Teoria crítica. Recepção. Intelectuais Brasileiros. Cultura

\begin{abstract}
:
Our purpose in this article is to reflect on what we consider to be the first phase of the receipt of the Critical Theory of the Frankfurt School in Brazil with emphasis on production of some Brazilian intellectuals who were pioneers this process, not only as translators and publishers of the Frankfurter thought, but also as interpreters of the national reality. In a troubled period of history, marked by repression of the military regime, intellectuals such as José G. Merquior, Roberto Schwarz, Gabriel Cohn and Flávio Kothe, in different theoretical nuances began to receive critical theory in Brazil, his immersion in the social sciences in the country and with repercussions as to the manner of understanding of the Brazilian society.
\end{abstract}

Keywords: Social theory. Critical theory. Reception. Brazilian Intellectuals. Culture

Originais recebidos em: 17/05/2012

Aceito para publicação em: 25/10/2012

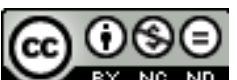

Comercial-Vedada a criação de obras derivadas 3.0 Unported License. 
É intenção deste artigo delinear alguns aspectos que caracterizam o processo de recepção da Teoria Crítica da Escola de Frankfurt no Brasil entre as décadas de 1960 e 1970. ${ }^{1}$ Nossa ênfase se coloca quanto à tentativa de apreensão do papel de alguns intelectuais brasileiros que protagonizaram este processo de recepção de diferentes formas. Intelectuais com formações diferenciadas, posições teóricas distintas, que confluem para a formação de um cenário histórico em que o conjunto de ideias de uma das mais expressivas correntes da teoria social contemporânea aportou no Brasil, foi passível não só de divulgação, como de interpretação, e passadas quatro décadas consolida-se como um dos importantes modelos de pensamento estudados tanto nas Ciências Sociais como no conjunto das Ciências Humanas.

Nosso enfoque se dará sobre o que consideramos ser a primeira parte desse processo de recepção (1968-1978), cuja datação traz certa arbitrariedade do pesquisador, mas que pretende, no andamento da exposição, justificar o porquê das datas apontadas. Acreditamos não existir, até o presente, estudos sistemáticos sobre tal processo de recepção, apesar da existência de alguns trabalhos dispersos sobre o tema, ${ }^{2}$ de modo que nosso ensaio pretende contribuir para a elucidação da maneira pela qual a chamada Escola de Frankfurt foi se consolidando no campo intelectual brasileiro, possuindo hoje um número considerável de estudiosos, pesquisadores e intérpretes.

Não obstante em diversos momentos, ao longo desses mais de quarenta anos, tenha-se feito referências ao pensamento frankfurtiano como representativo de algum tipo de moda intelectual, a sua consolidação nas Ciências Sociais do país tem mostrado um caminho diferente. Em uma ambientação intelectual em que as questões do subdesenvolvimento e da periferia têm se mostrado renovadamente relevantes para os pensadores do país, o processo de recepção sobre o qual vamos falar diz respeito não apenas a uma história das ideias, mas também ao modo pelo qual o legado da teoria crítica foi igualmente apropriado, de modos diversos, para pensar tal contexto.

A Teoria Crítica da Escola de Frankfurt teve sua inserção no Brasil a partir de meados da década de 1960 consolidando-se no final daquela década com as primeiras

\footnotetext{
${ }^{1}$ Agradeço aos pareceristas anônimos as valiosas contribuições de reflexão quanto ao tema proposto. Se algumas de suas sugestões não foram aqui incorporadas, o serão em eventuais desdobramentos deste artigo.

${ }^{2}$ Informações dispersas sobre este período de recepção encontra-se em: COUTINHO (1986); FREITAG (1990); PRESSLER (2006); CHACON (1977; 1994); COELHO (1999); LEO MAAR (2005); SILVA (2007); DUARTE (2009).
}

Em Debat: Rev. Dig., ISSNe 1980-3532, Florianópolis, n. 7, p. 126-149, jan-jul, 2012. 
traduções de obras de pensadores frankfurtianos, inicialmente alguns textos de Walter Benjamin, e depois Herbert Marcuse e Theodor Adorno. É possível afirmarmos que dois campos do conhecimento expressaram fortemente o impacto inicial do pensamento frankfurtiano: o dos estudos literários e da comunicação. As primeiras referências ao pensamento frankfurtiano ocorrem a partir de debates quanto à relação entre arte e sociedade, mesmo antes de 1968. Sugestivo quanto ao fato de que já na década de 1950 autores frankfurtianos não eram completamente desconhecidos no país encontra-se no relato de Vamireh Chacon que afirma ter mencionado publicamente Theodor W. Adorno pela primeira vez em 1955 (cf. CHACON, 1994, p. 454).

Em 1965, menos de um ano após o golpe militar no Brasil, Roberto Schwarz fará uso de conceitos centrais benjaminianos na coletânea de ensaios A Sereia e o Desconfiado, no mesmo ano em que José Guilherme Merquior menciona Benjamin em Razão do Poema, livro com orelha de Leandro Konder, outro que começava a se envolver nesse período com o pensamento de Walter Benjamin. Os temas em questão se referiam a um texto do autor alemão que será traduzido pela primeira vez no Brasil em 1968: “A obra de arte na era de sua reprodutibilidade técnica". Se uma nova geração de críticos literários começa a fazer menções a Benjamin ou Adorno, por outro lado não havia, em meados da década de 60, qualquer entendimento explícito sobre a ideia de teoria crítica ou mesmo sobre a noção de Escola de Frankfurt.

Embora a própria vinculação entre o nome de Benjamin e a Escola seja problemático (JAY, 1986), entendemos que as questões que permeiam a ideia de teoria crítica, principalmente no Brasil, estão diretamente associadas ao seu nome até hoje, sendo que entre 1968 e o final dos anos 1970 é ele o autor mais debatido por intelectuais do país entre os denominados frankfurtianos. Enquanto que o texto "a obra de arte" demarca a apreensão inicial dos conceitos de aura, alegoria e mimese, centrais em toda a obra benjaminiana, suas reflexões sobre a modernidade encontram eco entre nossos expoentes do pensamento já na metade dos anos 70, quando começa a tomar forma, principalmente na Europa, o longo debate entre modernos e pós-modernos. Em 1975, foi publicado o livro $O$ moderno e os modernos que incluía o famoso ensaio sobre Baudelaire, mais tarde reeditado nas Obras Escolhidas.

No final da década de 1960, e passagem aos 1970, os debates acerca da comunicação de massa se tornaram mais intensos na academia brasileira e mesmo fora dela, frente a um contexto em que já eram intensamente debatidas as questões sobre a cultura nacional e quanto ao próprio conceito de cultura. Se desde os anos 40 as Em Debat: Rev. Dig., ISSNe 1980-3532, Florianópolis, n. 7, p. 126-149, jan-jul, 2012. 
questões sobre a brasilidade, a identidade nacional, a busca por uma legítima cultura brasileira ocupava o centro de debates intelectuais no país, os anos 1960, antes e depois do golpe militar de 64, trouxeram ao âmago das preocupações de artistas, escritores e sociólogos debates sobre cultura que Marcelo Ridenti (2000), a partir de M. Löwy, chamou de um "romantismo revolucionário".

Não por acaso as primeiras leituras de Benjamin se associavam também ao vínculo deste com o teatro de Brecht, o dramaturgo alemão que dispunha então de uma ampla gama de seguidores e que refletia a ideia de que a cultura deve ter um telos transformador, engajado, revolucionário. Se por um lado Benjamin pôde inicialmente estar associado a um campo marxista do pensar a arte, no sentido de uma arte engajada que demarcava também os mecanismos de resistência ao autoritarismo, por outro, ele introduz os problemas quanto à relação entre arte e técnica, algo ainda pouco debatido nas discussões nacionais sobre cultura. A introdução deste debate, quase inexistente até meados dos anos 1960, ocorre no mesmo momento histórico de consolidação de uma indústria cultural no país, conforme a tese bastante conhecida de Renato Ortiz (1988).

Deste modo, também passaram a figurar no cenário cultural nacional, e de modos distintos, Marcuse e Adorno. Este último passou a ter, aliás, até o presente, seu nome sempre associado ao conceito de indústria cultural, embora seu pensamento tenha também se consolidado, já a partir dos primeiros anos da década de 1970, como um contraponto a algumas das teses defendidas por Benjamin sobre a relação entre arte, técnica e sociedade.

Embora algumas referências a Benjamin já fossem encontradas antes de 1968 (cf. MERQUIOR, 1965; SCHWARZ, 1965; KONDER, 1967), é somente a partir de um conjunto de traduções de textos dos pensadores frankfurtianos publicadas na Revista Civilização Brasileira que temos uma divulgação maior das questões da teoria crítica. ${ }^{3}$ O papel desta revista, publicada entre 1965 e 1968, foi fundamental como órgão de reflexão de intelectuais de esquerda nesse período, se constituindo, conforme depoimento de Konder (apud. SOARES, 1999, p. 89), no principal veículo de publicação de intelectuais de esquerda no período. O papel histórico desta revista na

\footnotetext{
${ }^{3} \mathrm{Na}$ Revista Civilização Brasileira encontramos dois artigos de Marcuse "Liberdade e Agressão na Sociedade Tecnológica" (n. 18, março/abril, 1968) e "Finalidades, Formas e Perspectivas da Oposição Estudantil nos Estados Unidos" (n. 21, set./dez. 1968). De Adorno "Moda sem tempo: Jazz" (n. 18, março/abril 1968). De Benjamin “A Obra de Arte na Era de sua Reprodutibilidade Técnica” (n. 19/20, maio/agosto 1968 .
}

Em Debat: Rev. Dig., ISSNe 1980-3532, Florianópolis, n. 7, p. 126-149, jan-jul, 2012. 
divulgação das ideias de Benjamin, Marcuse e Adorno é tão significativo que representa um marco no processo de recepção da teoria crítica no Brasil.

Em 1967 já havia surgido A Ideologia da Sociedade Industrial (O Homem Unidimensional) e em 1968 foram publicados dois outros livros de Marcuse; Eros e Civilização e Materialismo Histórico e Existência, abrindo uma sequência de traduções do autor que tem até 1973 seis obras publicadas por editoras brasileiras. Neste mesmo ano outra editora, a Tempo Brasileiro, que terá um papel igualmente decisivo na divulgação do pensamento frankfurtiano no Brasil, publica um dos primeiros textos de Sérgio Paulo Rouanet sobre a Escola de Frankfurt: o ensaio De Eros à Sísifo que sai na edição 17/18 da Revista Tempo Brasileiro. Contudo, Rouanet só se tornará efetivamente um emérito protagonista do processo de recepção da teoria crítica no Brasil a partir no final da década de 1970.

\section{II}

Foi também esta mesma editora que em 1969 publicou o livro pioneiro na inserção da Escola de Frankfurt no Brasil, a obra Arte e Sociedade em Marcuse, Adorno e Benjamin de José Guilherme Merquior, que além de propiciar algumas importantes interfaces entre teoria crítica e psicanálise, fez refletir em seus escritos a influência mundial que tinha Marcuse naquele momento histórico. O pioneirismo da obra de Merquior deve ser compreendido como algo que demarca a própria literatura internacional sobre teoria crítica, embora redigido originalmente em português. Basta lembrarmos que somente em 1973, surgiu a renomada obra histórica de Martin Jay [1973 (1986)] sobre a Escola de Frankfurt.

A obra de Merquior, cuja trajetória intelectual está longe de podermos identificálo como um seguidor da teoria crítica, e muito menos do marxismo, traz à tona um olhar acerca dos pensadores frankfurtianos que em parte reflete as mesmas críticas que tais pensadores viriam a receber em âmbito internacional. Ao mesmo tempo, abre um certo olhar, principalmente sobre Marcuse e Adorno, que tem uma repercussão duradoura na intelligentsia nacional. Merquior retoma a distinção adorniana entre alta cultura e cultura de massas, não se opondo à defesa que faz Adorno da obra de arte autônoma, mas ao mesmo tempo critica o "pensamento negativo" do pensador alemão, cujo 
apartamento de proposições políticas transformadoras o conduziria ao que mais tarde Habermas chamará de um "beco sem saída".

Se o mérito de Merquior esteve em ser pioneiro na recepção e divulgação da teoria crítica no Brasil, a parcialidade de sua interpretação, principalmente quanto a Adorno, demonstra uma leitura no mínimo apressada do pensador frankfurtiano. O livro de Merquior se divide em três partes: na primeira ele aborda Marcuse e Adorno; na segunda, Walter Benjamin; e em uma terceira parte as possíveis respostas da ontologia heideggeriana aos impasses frankfurtianos. Embora desconhecesse a ainda não publicada Teoria Estética de Adorno, acusa este de conceber a possibilidade da obra de arte autônoma no sentido de uma promessa de felicidade perdida, e, portanto, negativamente destinada à impossibilidade da utopia (MERQUIOR, 1969, p. 56). Da mesma forma, a crítica que fazia Marcuse da sociedade industrial teria conduzido este a algo não além do que a postulação da conhecida "grande recusa". Marcuse e Adorno são interpretados como prisioneiros de um impassível pessimismo, o que se confirma em um trecho da terceira parte do livro:

\footnotetext{
O utopismo "pedagógico" schilleriano, de Marcuse, e a amargura autofágica da estética de Adorno são repassados da consciência da preguiça da práxis, do senso de ausência de um horizonte revolucionária. Todo messianismo é iminentista. Como a revolução não se apressa, o traço messiânico se transforma em pessimismo agudo. Em todo caso, o apagamento do messianismo não se verifica só no marxismo de Frankfurt (MERQUIOR, 1969 , p. 255-256).
}

Embora na segunda parte do livro suas posições sejam mais amenas quanto a Benjamin, havendo uma aproximação a este que irá perdurar por muitos anos depois, Merquior, antes de sua imersão no estruturalismo, se mostra ainda muito vinculado a Heidegger, e como diz Duarte (2009), sem conseguir justificar, entre outras coisas, sequer a relação daquele com o nazismo. Mas como mostrou a história, o conservadorismo de Merquior nunca chegou a tanto, apesar de sua relação cavalheiresca com o regime militar, e sua refinada e quase apaixonada defesa do pensamento político liberal.

Será também a Tempo Brasileiro que publica a primeira tradução de um texto de Habermas em 1970 na coletânea Humanismo e Comunicação de Massa organizada por V. Chacon. Embora Habermas ao final dos anos 1960 já tivesse publicado alguns textos que são marco inicial de sua guinada na teoria crítica, até então sua obra mais conhecida Mudança Estrutural na Esfera Pública, não o alçava ainda a posição de um pensador de renome mundial. E mesmo que seu pensamento já fosse conhecido no Brasil, como 
vemos nos trabalhos iniciais de Gabriel Cohn (1968 a; 1971; 1973) naquele momento as questões que balizavam suas ideias sobre a esfera pública ainda estavam distantes de serem assimiladas, na medida em que vivíamos um contexto em que intelectuais eram exilados, o AI-5 impunha o silêncio, e os resquícios do romantismo revolucionário ainda predomina entre os pensadores de esquerda.

No final dos anos 1960 Marcuse fazia um grande sucesso em todo o mundo, frequentando até mesmo os meios de comunicação (SOARES, 2010), enquanto que Adorno ocupava-se de problemas sociológicos e com a finalização de sua Teoria Estética, antes de falecer em 1969. ${ }^{4}$ Instigante quanto à história de nossas Ciências Sociais é o pouco conhecimento que existia no Brasil acerca da controvérsia entre Adorno e Popper, que marca fortemente a teoria sociológica nos anos 1960, e que de algum modo, quanto à perspectiva de Adorno, contrastava com a forte tendência existente na sociologia brasileira em privilegiar a pesquisa empírica como marco distintivo na busca de consolidação da sociologia como disciplina científica.

Percebemos uma tendência em considerar que o período inicial de recepção da teoria crítica de Frankfurt coincide com os acontecimentos de 1968 (COUTINHO, 1986; SOARES, 2010), marcado pela tradução de alguns textos de Marcuse que se tornava naquele momento uma referência, nem sempre bem interpretada, para o movimento estudantil e depois, de forma ainda mais incongruente, pelos divulgadores da contracultura. Como observa Arantes (2004, p. 150), tanto entre professores já renomados como entre estudantes, esta recepção de um pensador que repentinamente tornara-se pop trazia equívocos de leitura que se prolongaram nas décadas seguintes.

Passadas mais de quatro décadas daquele contato inicial com Benjamin, ainda hoje predomina a ideia de que este era o mais marxista dos frankurtianos, e em alguma medida por isso, certa reverência que ele passou a dispor por parte de intelectuais de esquerda, cuja inegável predileção por Gramsci ou Lukács, remonta aos distantes anos 1960. As afinidades com Benjamin, contudo, desde então se mostraram como algo bem mais próprio aos intelectuais envolvidos com a crítica literária e a estética do que com os sociólogos, para os quais Benjamin talvez seja filósofo em demasia, embora uma parte central da constelação teórica benjaminiana, sempre tenha sido a mesma que de

\footnotetext{
${ }^{4}$ O pequeno, mas nada simples texto de Adorno "Capitalismo Tardio ou Sociedade Industrial?" havia sido uma conferência durante o $16^{\circ}$ Congresso de Sociólogos Alemães em 1968. Inúmeros outros textos de Adorno sobre temáticas sociológicas datam da década de 1960.
} 
Adorno e Marcuse: a crítica do fetichismo da mercadoria e da exacerbação contemporânea do valor de troca.

Peculiar quanto à recepção da teoria crítica no Brasil é que os intelectuais que sorvem a letra, sempre complexa, dos frankfurtianos, não eram apenas os marxistas, e também não pertencem apenas ao campo acadêmico, como mostra o próprio exemplo de Merquior. Podemos afirmar, mais do que isso, que alguns dos primeiros divulgadores e intérpretes frankfurtianos não são "frankfurtianos", no sentido de intelectuais articulados em torno de uma visão de mundo impressa pela "ideia original de teoria crítica”, para lembrarmos o programa inaugural de Max Horkheimer [1937 (1983)]. Ao mesmo tempo, principalmente nos anos 1970, houve uma clara aproximação de Schwarz e Cohn aos fundamentos da teoria crítica, mas não acreditamos ser esse o caso de outros importantes expoentes desse mesmo processo histórico, como Konder, Coutinho, Chacon, e principalmente Merquior.

Já nos primeiros anos da década de 1970 viu-se arrefecer aquela quase festiva recepção inicial de Marcuse, como diz Coutinho (1986) manifestando-se, por outro lado, algum interesse pelas obras de outros representantes da teoria crítica, inclusive de seu representante da chamada segunda geração, Jürgen Habermas. Mas, a importância deste surgirá bem mais tarde. Logo no início dos anos 70 surgem as primeiras traduções de livros de Adorno, assim como alguns capítulos de livros (LIMA, 1970; COHN, 1971).

Enquanto Habermas ainda era pouco conhecido pelos intelectuais e sociólogos brasileiros, este período foi bastante propício para o amadurecimento do interesse pelos temas da cultura de massas e da indústria cultural. Naquele momento, se consolidava no país uma indústria das comunicações nos moldes criticados pelos frankfurtianos, isto é, a consolidação tanto de um aparato publicitário formado em padrões administrativos, como de uma indústria editorial, televisiva, fonográfica e de cinema que não era perceptível no país em décadas anteriores (cf. ORTIZ, 1988). Surgem deste modo, os primeiros trabalhos nos campos da sociologia da cultura e da sociologia da comunicação tomando como referência as obras de Adorno e Horkheimer.

Se Marcuse foi interpretado por boa parte dos intelectuais brasileiros como pensador que de alguma forma inspirava os movimentos da contracultura, ou mesmo de certo irracionalismo, esta foi expressão de leituras e debates que se deram mais em cafés e ambientes externos às discussões acadêmicas. Esfera acadêmica esta na qual o autor de Razão e Revolução jamais chegou a se consolidar. E quando esta existiu, esteve 
muito mais próxima dos filósofos, nos anos 1960 também influenciados fortemente pela fenomenologia, o que permitia ver em Marcuse um pensador não identificado ao marxismo tradicional, mas portador de uma abertura que incluía também a sua releitura da psicanálise.

Em Humanismo e Comunicação de Massa (1970) Chacon reintera algumas percepções sobre teoria crítica, já presentes em Merquior, manifestando uma interpretação, principalmente de Adorno e Horkheimer, comum entre muitos intelectuais brasileiros:

Frankfurt, por sinal, já aparecera despertando polêmicas quanto à sua filiação: uns chamando-a de marxista, outros de neo-hegeliana de esquerda, ou ambas as coisas, paradoxalmente, ao mesmo tempo. Na realidade a melhor catalogação, apesar de todos os perigos, continua a de Hegelianismo quase anárquico, mais descendentes de Schopenhauer e Nietzsche que dos jovens hegelianos, atacados por Marx n'A Sagrada Família (p. 14).

Embora Nietzsche tenha sido um filósofo nada desprezível para Adorno, e Schopenhauer tenha tido grande influência em Horkheimer, logo percebemos a grande dificuldade em compreender-se a relação entre teoria crítica e dialética. Como veremos adiante, esta aproximação da crítica frankfurtiana da razão com o irracionalismo, em mais de um momento impulsionou a leitura brasileira desses autores, que somente na década de 1980, com a influência de Habermas, terão ainda mais elementos para esta forma bastante questionável de interpretação.

\section{III}

A ideia de uma teoria crítica, como expressão de determinada forma de pensar a ciência e a sociedade, também não foi o viés através do qual Theodor Adorno passou a ser lido e conhecido no Brasil a partir da década de 1970, apesar das leituras e interpretações pioneiras de Gabriel Cohn no campo da sociologia da comunicação. Para os pesquisadores em Ciências Sociais Adorno desde o início, assim como Horkheimer, esteve associado ao conceito de indústria cultural, apreensão que acabou predominado nas décadas seguintes. Apesar da atualidade paradoxal do conceito de indústria cultural, que ao menos no campo sociológico se tornou relevante como uma referência central ao falar-se de Escola de Frankfurt, ao mesmo tempo passou a ser um tema isolado de reflexão acerca dos temas sociológicos de Adorno.

Antes de publicar a coletânea de textos Comunicação e indústria cultural (1971) Cohn havia sido tachado por Florestan como demasiado apegado aos preceitos 
weberianos em sua dissertação sobre o petróleo, ${ }^{5}$ que embora pouco condizente com o efetivo ideário teórico do sociólogo, já dizia algo de um jovem pensador que não se situava exatamente no campo dos renomados intelectuais marxistas, então representados por nomes como Caio Prado Júnior, Leandro Konder, Carlos Nelson Coutinho ou mesmo os herdeiros do Seminário de Marx. E não podemos desconsiderar como diz Paulo Eduardo Arantes (1989), a importância que veio a ter o pensamento marxiano no interior do debate acadêmico entre as décadas de 1960 e 1970, muito embora, como diz Schwarz (2005), mediante interpretações que corriam ao largo de entrever o efetivo significado do "fetichismo da mercadoria" como aspecto central para a compreensão das transformações pelas quais passava a nação.

Um pouco antes do livro organizado por Cohn, Luiz Costa Lima inaugurava os trabalhos em sociologia da comunicação com seu pioneiro Teoria da Cultura de Massa (1970) onde aparecem ensaios de Adorno, Horkheimer, Marcuse e Benjamin, ao lado de pensadores canônicos no tema cultura de massas. Obra que em 2005 já se encontrava em sua $7^{\mathrm{a}}$ edição traz uma das traduções do período do texto "a indústria cultural”, o debatido "a obra de arte" de Benjamin, e "A Arte na Sociedade Unidimensional" de Marcuse.

No mesmo ano em que defende sua dissertação sobre Petróleo e Nacionalismo no Brasil (1968b) Gabriel Cohn começa a mostrar uma nova fisionomia na teoria social brasileira. Na contramão de uma visão corrente de que no contexto periférico a sociologia deve privilegiar a compreensão deste próprio contexto, relegando a elaboração teórica aos expoentes dos países centrais. Cohn inicia uma larga, e ainda viva trajetória, de consolidação da teoria social no Brasil. Em 1968 publica também na Revista Civilização Brasileira o artigo “A sociologia e a arte da controvérsia” (1968a), no qual, mesmo sem ainda evidenciar a crucial influência frankfurtiana em seu pensamento, já aponta para posturas ousadas ao lidar com os problemas da relação entre teoria e empiria, manifestando, tal como insistiu Adorno ao longo de toda a década de 1960, a impossibilidade da emancipação sem a existência do rigor teórico.

Na coletânea de 1971, além de dois textos de sua própria autoria, Cohn traz a tradução de um texto de Habermas, e dois ensaios de Adorno, um dos quais o clássico "a indústria cultural” que já havia aparecido na coletânea de Luiz Costa Lima. Aqui já se antecipa alguns dos temas que surgirão em Sociologia da Comunicação - teoria e

\footnotetext{
${ }^{5}$ O trabalho de Cohn Petróleo e Nacionalismo foi publicado ainda em 1968. Acerca da declaração de Florestan ver a entrevista de Gabriel Cohn em: BASTOS, 2006, p. 116.
} 
ideologia (1973) obra de rara feitura na teoria social brasileira. Os temas são a contraposição então em voga entre massa e elite, a diferenciação entre sociedade de massa e cultura de massa, o público e a mensagem, a posição, enfim, da comunicação quanto ao seu estatuto na relação entre produção e consumo.

As duas obras são consideradas pioneiras na então nascente sociologia da comunicação, cuja história, desde então, mostrou tratar-se de uma disciplina de difícil consolidação no campo das Ciências Sociais (cf. DIAS, 2008). Assim como outros grandes nomes da sociologia brasileira Cohn, desde os seus primeiros trabalhos, insiste na reflexão sobre a condição da sociologia como ciência, o que não impede que principalmente em seus textos de maturidade a "forma do ensaio" venha a expressar uma maneira própria de pensar a relação entre teoria crítica, sociologia e conhecimento.

Após delinear o conjunto de problemas que caracterizariam uma chamada sociologia da comunicação Gabriel Cohn (1973) estabelece diálogo com parte considerável dos principais teóricos da sociologia contemporânea, levantando problemas que extrapolam o campo específico da comunicação, e que podem ser mais bem situados como teórico-sociais. Nos dois capítulos finais de seu livro o Autor apresenta, num tom que parece ser até mesmo de alívio, quais são afinal suas principais referências sobre o tema da comunicação, e porque não dizer, como ficará claro nas décadas seguintes, de sua própria compreensão teórica da sociedade:

Nesse ponto, chegamos ao final de nossa caminhada neste capítulo, na
medida em que se abre a possibilidade de introduzir na discussão aquela linha
de pensamento que, segundo a entendemos, representa, a síntese de tudo
aquilo que há de cientificamente relevante nas proposições examinadas antes,
acrescida de elementos próprios da maior importância. Trata-se da
perspectiva representada pela chamada "escola de Frankfurt" que se reuniu
(até a sua recente dissolução) em torno de Max Horkheimer, e cujo
representante máximo, naquilo que concerne ao presente trabalho, é Theodor
W. Adorno (COHN, 1973, p. 124).

Uma década após publicar este livro Cohn já se consolidava no cenário intelectual brasileiro como grande intérprete da teoria crítica da sociedade. Suas traduções de textos sociológicos adornianos são até hoje a mais importante referência bibliográfica em português nessa área. ${ }^{6}$ Mas antes disso, houve Max Weber e a original exposição do Autor no final dos anos 1970 sobre o sociólogo alemão. Ao invés de acreditarmos que Cohn esquecera Frankfurt enquanto dedicou-se ao denso trabalho sobre Weber, o que fica evidente é o contrário. Não obstante ele ter afirmando em Sociologia da Comunicação (1973, p. 126) que os textos de maturidade de Adorno

\footnotetext{
${ }^{6}$ Referimo-nos a coletânea de textos publicada pela editora Ática em 1986: Adorno - Sociologia.
} 
apreendiam a noção de indústria cultural em um sentido muito mais enfaticamente centrado no fetichismo da mercadoria de Marx, do que no tema da racionalização de Weber, será este mesmo Weber quem consolida certo modo de lidar com o modelo frankfurtiano.

Referimos-nos aqui, e concordando em boa medida com a interpretação de José Maurício Domingues (2011) quanto à ideia de que o conceito de dominação constituise, desde esta época, na questão central, mas poucas vezes explícita, das formulações sociológicas de Cohn. Não devemos esquecer, aliás, que a dominação é também o grande tema de toda a obra de Adorno (HONNETH, 1991), autor que Gabriel Cohn não esconde ser o seu predileto no amplo espectro da teoria social contemporânea. Em uma época em que poucos ousavam dedicar-se fundamentalmente à teoria, aliás, como até hoje, a posição de Cohn parece também ser um pouco singular, não só no campo sociológico, como o comparando com outros expoentes deste período na recepção do pensamento frankfurtiano.

Enquanto J. G. Merquior no início dos anos 1970 assumia posições políticas mais conservadoras e teoricamente se mostrava cada vez mais próximo do estruturalismo, pensadores como Konder e Coutinho representavam o que podemos chamar de marxismo tradicional, sem qualquer conotação pejorativa ao termo, com incursões significativas no campo filosófico. Com Roberto Schwarz dedicando-se a teoria literária, Gabriel Cohn era nesse momento uma voz quase solitária na sociologia brasileira. Entendemos que Cohn apreende naquele momento não aquilo que é o mais central dentro da trajetória frankfurtiana, mas nesta trajetória, o que era mais significativo para aquele processo histórico da realidade brasileira, a compreensão do fenômeno da indústria cultural, até então um tema secundário nos debates nacionais, ainda há pouco centralizados nas questões sobre a brasilidade e a identidade nacional.

A evidência de que o problema da indústria cultural, para alguns da cultura de massas, tornava-se um tema emergente nas Ciências Sociais, se expressa na elaboração de algumas teses de mestrado e doutorado que passam a ser produzidas pelo país, principalmente na USP, nos primeiros anos da década de 1970. Embora estas pesquisas iniciais não evidenciassem em sua feitura a pretensão de uma prática sociológica 
ancorada, em sentido metodológico e epistemológico, em uma teoria crítica da sociedade, marcaram significativamente a história recente das Ciências Sociais no país. ${ }^{7}$

Adorno e Horkheimer passam a ter, a partir desse contexto, uma pequena gama de seguidores em campos diversos das ciências humanas, mas praticamente ignorados nos cursos de Filosofia, por exemplo, onde a efetiva penetração do pensamento frankfurtiano só foi ocorrer a partir do advento da segunda geração da teoria crítica personalizada em Habermas. Apesar disso, alguns outros textos importantes de Adorno e Horkheimer também tiveram tradução para a língua portuguesa, como o hoje esgotado Temas Básicos de Sociologia (1973), Notas de Literatura (1973) e Filosofia da Nova Música (1974).

Se já nesse período o pensamento de esquerda e as próprias iniciativas editoriais começam a demonstrar maior interesse por pensadores como Gramsci e Lukács, não se pode ignorar que pensadores que de algum modo estiveram próximos ao pensamento frankfurtiano também já circulavam em língua portuguesa, como é o caso de Erich Fromm com incontáveis traduções desde 1960 e o instigante livro de Ernest Bloch sobre Thomas Münzer publicado em $1974 .^{8}$

\section{IV}

Dentre aqueles intelectuais responsáveis pela introdução da Escola de Frankfurt no Brasil, possivelmente Roberto Schwarz tenha sido aquele que mais enfaticamente, embora não menos sutilmente, ocupou-se de temas tipicamente nacionais iluminado-os com conceitos da teoria crítica. Isto se refere tanto à originalidade com que se consolidou na crítica literária, quanto aos seus textos diretamente relacionados a uma interpretação do país. A presença dos frankfurtianos em seu pensamento já é visível no início dos anos 1960, desde o pioneiro A Sereia e o Desconfiado (1965). Naquele momento o seu interesse pela obra de Adorno já era tão significativa que quase havia ido para Alemanha estudar com o mestre alemão (cf. ALMEIDA, 2007, p. 45).

\footnotetext{
${ }^{7}$ Destaque para Sérgio Miceli com "A Noite da Madrinha (1972), e Maria Arminda do Nascimento Arruda com a "A Embalagem do Sistema" [1979 (1985)], além das teses de Eclea Bosi; Angeluccia Habert; Othon Barbosa; Orlando Pinto de Miranda e várias outras.

${ }^{8}$ Embora enfatizemos a papel central das traduções ao português nesse processo de recepção, no início dos anos 1970 diversos pesquisadores se utilizam de versões em espanhol ou mesmo em francês das obras produzidas pelos autores frankfurtianos.
}

Em Debat: Rev. Dig., ISSNe 1980-3532, Florianópolis, n. 7, p. 126-149, jan-jul, 2012. 
Schwarz trazia em sua bagagem os ensinamentos de Antonio Candido e a experiência do Seminário de Marx, afora que em suas formulações proponha um "ecletismo" bem distinto daquele de Florestan Fernandes, pois é um ecletismo do campo marxiano, que inclui Lukács, Benjamin, Adorno e Brecht. Assim como no caso de Gabriel Cohn ousamos afirmar que Adorno é a influência mais perceptível de seu pensamento. E tanto em um caso como em outro, influência significa a incorporação de uma forma de pensar a sociedade que dispensa as facilidades, os atalhos conceituais e o caminho mais curto no ato de elaboração teórica.

Como poucos Schwarz mostra ter entendido o que Adorno chamava de crítica imanente, e tal entendimento se manifestou na forma de uma exposição coerente do pensamento de Adorno, mas como algo incorporado seja em suas críticas da literatura, ou em seus ensaios de interpretação da realidade nacional. Muito conhecidos são seus textos "Nota sobre vanguarda e conformismo" (1967) e "Cultura e Política, 1964-1969", ambos publicados em O Pai de Família e Outros Estudos (1978), em que o Autor pensa o papel dos intelectuais em moldes não muito comuns naquele momento histórico.

Já ambientado na rica crítica frankfurtiana da noção de "progresso", consegue apreender no âmbito da música, do cinema, do teatro e da literatura que marcam a passagem dos anos 1960 aos 1970, os traços daquilo que já era claro na Alemanha e principalmente nos Estados Unidos há mais de duas décadas, e que viria a ser também no Brasil, isto é, o entrelaçamento entre cultura e mercado, em formatos que se autoconsituíram até mesmo como crítica deste processo: "Vendeu-se, está criticando, ou vendeu-se criticando?” (SCHWARZ, 1978, p. 48).

Ainda mais polêmico é o ensaio de Schwarz “As ideias fora do lugar” escrito em 1973 e republicado no paradigmático Ao Vencedor as Batatas (1977) em que a literatura brasileira do sec. XIX é interpretada como forma estética de elucidação de uma experiência capitalista em grande medida singular, ao gosto de muitos, chamada de periférica. Mas tal experiência, para Schwarz, não deixa de ser vista a partir de uma recorrência, mesmo implícita, a seus mestres Lukács e Adorno com seu conceito de totalidade. $\mathrm{O}$ valor e o trabalho abstrato não estão ausentes do contexto periférico, digase, não explicitamente pensado por Adorno, mas assumem peculiaridades que são traços da sociedade brasileira, alguns destes já antes apontados por Sérgio Buarque de Hollanda, e que Schwarz mostra como uma modernidade descompassada. Como diz Miceli (2007) sobre a interpretação de Schwarz quanto ao primeiro Machado de Assis: 
Ou, por outro lado: no grande realismo a figuração da totalidade da vida concreta dos homens só podia se realizar através da figuração do papel central do dinheiro, o que não vale tal e qual na periferia, onde operam com atualidade formas arcaicas - sobretudo as relações paternalistas. Daí o romance da primeira fase esta às voltas com o oximoro do 'obséquio impessoal' que Roberto Schwarz expõe à luz do dia na análise penetrante dos primeiros romances (p. 39-40).

A totalidade, assim, se dialetiza negativamente na dualidade. Ao pesquisador brasileiro que só tardiamente teve acesso a Dialética Negativa de Adorno, ${ }^{9}$ talvez valha a pena ler com cuidado a original interpretação de Schwarz da obra de Machado de Assis, para ver como uma teoria crítica da sociedade pode ser esclarecedora não só nos rigorosos parâmetros das pesquisas sociológicas empíricas, mas também nas sutilezas da crítica literária. Aqui, a dialética do universal e do particular, a contradição e a recusa da síntese, o não idêntico que se afirma enquanto tal, se refletiu na interpretação de "Helena" ou "Iaiá Garcia" [SCHWARZ, 2000 (1977a)], como a manifestação de uma dominação capitalista que se expressa na forma de relações patriarcais e paternalistas, que tornam explícitas a realidade escravocrata como constância contraditória na formação da sociedade brasileira.

Enquanto que há, em nosso entendimento, uma sutil preferência por Lukács e Adorno na forma de crítica empreendida por Schwarz, na metade dos anos 1970 outro importante intelectual surgirá no cenário nacional como responsável pela consolidação das ideias frankfurtianas no país a partir de uma evidenciada predileção pelas ideias de Benjamin. Trata-se de Flávio René Kothe. Enquanto Schwarz já incorporava procedimentos da teoria crítica em seus ensaios sobre a realidade nacional, não escrevendo qualquer estudo sistemático sobre este ou aquele dentre os pensadores de Frankfurt, diferente será o papel cumprido por Kothe. Autor de dois livros que até hoje são referências entre o público brasileiro no estudo de Benjamin, empreendeu uma pesquisa sobre Adorno e Benjamin que naquele momento era original não só no Brasil, mas em nível internacional, como o fora antes Merquior, até hoje não suficientemente reconhecida pelo campo intelectual do país.

Também vitimado pelas perseguições do regime militar as contribuições de Kothe, que se consolidaram nas décadas seguintes, foram cruciais para a introdução do pensamento frankfurtiano no Brasil tanto no âmbito da crítica literária, da filosofia como da teoria social. Em 1975 defendeu a primeira tese de doutorado no país sobre um

\footnotetext{
9 Esta, que pode ser considerada a principal obra de Adorno, teve sua primeira tradução no Brasil publicada em 2009 pela editora Zahar. Aos estudiosos, antes disso, restavam traduções em inglês, espanhol ou a leitura no original em alemão.
}

Em Debat: Rev. Dig., ISSNe 1980-3532, Florianópolis, n. 7, p. 126-149, jan-jul, 2012. 
pensador da Escola de Frankfurt que resultou no livro Benjamin \& Adorno: Confrontos (1978). Já em 1976 havia publicado o primeiro livro introdutório sobre Benjamin no Brasil, onde apresenta ao público, de uma forma clara, as principais ideias do autor de $A$ Origem do Drama Barroco Alemão.

Um dos aspectos da originalidade deste livro de Kothe está em esquadrinhar as diferenças entre Benjamin e Adorno, sobretudo quanto à compreensão do papel da tecnologia frente à utopia da obra de arte autônoma. Discussão que se por um lado balizava o próprio ambiente de recepção dos frankfurtianos no início dos anos 1970, por outro, ainda não havia sido meticulosamente estudado, como se poderia supor, nem mesmo na Alemanha. Descendente de alemães que haviam chegado ao sul do Brasil em situações adversas, Kothe tornou-se reconhecido no campo intelectual brasileiro sem deixar de trazer o marco de certo estranhamento principalmente quanto a inúmeros de seus pares do campo acadêmico. Com mais de uma estada na Alemanha, foi responsável por traduções significativas, como a edição de $O$ Capital da coleção Grandes Economistas, além de textos dos próprios frankfurtianos.

Sempre atento aos desdobramentos do fetichismo da mercadoria, com destaque para o campo literário, Kothe não deixa barato a quase naturalizada metamorfose da palavra em mercadoria. Ao contrário de Merquior, e não só quanto às orientações ideológicas, sua pesquisa foi inteiramente realizada com fontes primárias, com base em centenas de textos de Benjamin e Adorno, elucidando ao público brasileiro conceitos benjaminianos que só mais tarde se tornariam amplamente debatidos como mimese, aura, alegoria, experiência. Também diferente de Schwarz e Cohn, a leitura que Kothe fez de Adorno foi bastante dura, com acusações pouco polidas ao autor da Dialética Negativa, corroborando, mesmo indiretamente, uma leitura comum da obra de Adorno, que conforme entendemos, consolidou-se no Brasil nas décadas seguintes, mas que encontra em sua letra, como naquela de Merquior, formas duradouras de interpretação.

Assim como no caso de nomes expressivos da sociologia e da filosofia contemporânea, também os pensadores frankfurtianos, já nesse primeiro período de recepção, foram passíveis de críticas e formas de interpretação que se dão à margem de sua leitura, ou, de uma leitura bastante parcial de suas obras. Na metade dos anos 1970 apenas o texto sobre a indústria cultural havia sido traduzido para o português da mais paradigmática obra da Escola de Frankfurt que é a Dialética do Esclarecimento. ${ }^{10} \mathrm{Na}$

\footnotetext{
${ }^{10}$ A primeira tradução do livro em versão integral só aparecerá em 1985, pela editora Jorge Zahar, em trabalho realizado por Guido A. de Almeida.
}

Em Debat: Rev. Dig., ISSNe 1980-3532, Florianópolis, n. 7, p. 126-149, jan-jul, 2012. 
edição da coleção "Os Pensadores" da Editora Abril Cultural (1975) o lapidar excurso sobre o "conceito de iluminismo" foi traduzido por Zelijko e Andéa Loparic, que junto a outros ensaios centrais sobre teoria crítica pode ser visto como outro marco na recepção da Escola de Frankfurt no Brasil. Outros textos importantes, por outro lado, só tiveram traduções na década de 1980, como é o caso dos volumes publicados na coleção "Sociologia" da editora Ática.

Se a tese da indústria cultural teve para alguns pensadores o caráter de uma descoberta, afinal iluminava teoricamente o espetáculo incipiente dos meios de comunicação de massa no país, com destaque ao aprimoramento técnico da indústria televisiva, o seu estudo efetivo, principalmente por parte dos intelectuais de esquerda, teve vida curta. Saídos das longas discussões sobre a cultura nacional, embrenhados na necessidade de explicar a natureza da cultura popular, o entendimento sobre a relação entre indústria cultural e racionalidade moderna se tornou em muitos casos em falta de entendimento quanto ao significado da teoria crítica. A partir de uma leitura rápida de Adorno e Horkheimer se consolidaram os estereótipos acerca do negativismo, do pessimismo, da ausência de um telos programático que invalidaria a crítica frankfurtiana da modernidade.

Mesmo Carlos Nelson Coutinho, um incentivador da divulgação dos frankfurtianos no país, protagonizou no campo das ideias marxistas, o que outros nada marxistas como Merquior e Rouanet igualmente expressaram em diferentes momentos, uma grande preocupação em denunciar o irracionalismo, seja como expressão de uma prática política insinuante desde o maio de 1968, seja como ruptura epistemológica, também ceivada de consequências políticas, formuladas a partir de um recrudescimento de Nietzsche no meio intelectual francês.

Foi desse modo que a crítica racional da razão de Adorno e Horkheimer facilmente passou a ser aproximada das tendências irracionalistas, na medida em que a chamada razão negativa de Adorno manifestava não só uma ausência de normatividade política, como se apartava, aparentemente, do ideário da Aufklärung. Mas tal leitura sobre as heranças kantianas serão a marca do segundo período de recepção. Sobre o período histórico que estamos falando era visível uma crítica ainda mais evidente, espantosa para os militantes de esquerda, de que o proletariado não seria mais o portador de um processo revolucionário. É assim que, paradoxalmente, a ideia mais ou menos evidente e até simpática para os intelectuais críticos ao "status quo" acerca da 
existência de uma indústria cultural no país, passa ao largo de ser estudada de uma forma mais efetiva. Havia, ao que parece, questões mais prementes.

Ao mesmo tempo em que a luta armada evidenciara a sua fragilidade como forma de resistência ao regime, este dava seus primeiros sinais de abertura, enquanto que o movimento sindical aos poucos se rearticulava para emergir como o grande fato político do final da década dos 1970. Diante das manifestações sociais, da eclosão das greves do $\mathrm{ABC}$, do retorno de alguns exilados, nada mais estranho do que um discurso teórico, como aquele de Adorno e Horkheimer, acerca da incapacidade histórica do proletariado. $\mathrm{O}$ que começava a se apresentar como importante era então já não mais a crítica da indústria cultural, uma crítica pouco duradoura, que só ressurgirá com alguma força mais tarde, pois as questões relativas à democracia, a esfera pública e a soberania popular se tornavam centrais.

No campo daqueles que, apesar da urgência histórica, não deixaram de pensar as questões da cultura, no amplo espectro do que podemos chamar de reflexão acerca da obra de arte, a aceitação das ideias de Benjamin parece ter sido menos afeita ao exercício da controvérsia. Nesse período, que vai até 1978, exceto Gabriel Cohn, que desde o início expressou uma afinidade eletiva com a teoria da sociedade de Adorno, os demais protagonistas da recepção frankfurtiana no país sempre mantiveram algum grau de aproximação com as ideias de Benjamin. Um estreitamento que implicava também o importante papel de Brecht para os artistas e intelectuais brasileiros, e que afinal de contas sempre esteve mais próximo de uma prática cultural portadora, para usar o termo de Bloch, dotada de esperança.

\section{$\mathbf{V}$}

Buscamos neste artigo, entre a informação histórica e a forma do ensaio, privilegiar alguns intelectuais que consideramos protagonistas do processo de recepção da teoria crítica no Brasil mediante um recorte que pode não fazer justiça a um espectro bem maior de pensadores que também tiveram nesse processo uma importância singular. Mas seria demasiado pretencioso em um pequeno ensaio nomear a todos, assim fizemos escolhas que refletissem certa pluralidade. A história aqui narrada ainda está por ser contada com mais detalhes, nuances e personagens, mas acreditamos ter indicado ao menos os protagonistas. Esta história também continua viva, tanto por sua 
personificação nos mesmos autores aqui mencionados, quase todos ainda muito atuantes no cenário intelectual brasileiro, como pelo fato de que os elementos de recepção presentes entre 1968-1978 continuam presentes no debate atual.

Embora a recepção de Frankfurt nesse período esteja associada, como vimos, ao papel de intelectuais de esquerda, a leitura da teoria crítica no âmbito da Comunicação ou da Filosofia no Brasil também mereceria uma atenção específica. Nosso olhar, nesse ensaio, termina ao final dos anos 1970, quando uma segunda fase de recepção se relaciona homologamente a uma segunda geração de pensadores da teoria crítica, principalmente Habermas, a partir do qual novas questões, novos intérpretes, e até mesmo uma nova configuração da realidade histórica passa a dominar no campo intelectual brasileiro. A partir daí novos pesquisadores, estudiosos e problemas surgirão, demarcando outra etapa desta história (CAMARGO, 2012), e ainda pouco narrada, quanto às fisionomias que marcam a recepção da teoria crítica no Brasil.

No apagar das luzes deste pequeno artigo duas novidades editoriais trazem à tona problemas aqui arrolados. O último livro de Roberto Schwarz (2012) traz a reprodução de uma entrevista sobre Adorno reiterando algumas das observações que fizemos acima, e por outro lado sai a tradução para o português da Correspondência Adorno-Benjamin (1928-1940) ${ }^{11}$ cujo conteúdo é fundamental para compreender-se não apenas a trajetória da Escola de Frankfurt, mas para a desmistificação de algumas impressões que se consolidaram entre nós, desde o início dos anos 1970, sobre o pensamento e atuação intelectual tanto de Benjamin como de Theodor Adorno. Assim, para que o leitor não ache que nossa interpretação da recepção esquiva-se de posicionamentos epistemológicos, concluímos com frase de Schwarz sobre Adorno:

É uma liberdade e diferenciação de espírito que não estamos acostumados e que, talvez por irritação, leva muitos à extravagante objeção a uma suposta torre de marfim. Aliás, a existência civil do espírito crítico é um fato político importante, muito raro, possivelmente mais radical do que a filiação partidária. Sem esquecer que Adorno não fez as pazes com capital (2012, p. $50)$.

\footnotetext{
${ }^{11}$ São Paulo; Editora da Unesp; tradução de José Marcos Mariani de Macedo e introdução de Olgária Matos.

Em Debat: Rev. Dig., ISSNe 1980-3532, Florianópolis, n. 7, p. 126-149, jan-jul, 2012.
} 


\section{Referências Bibliográficas}

ALMEIDA, Jorge de. Pressupostos, salvo engano, dos pressupostos, salvo engano. In: CEVASCO, Maria Elisa e OHATA, Milton (Org.). Um crítico na periferia do capitalismo: reflexões sobre a obra de Roberto Schwarz. São Paulo: Companhia das Letras, 2007, p. 44-53.

CAMARGO, Sílvio. Itinerários da Teoria Crítica na Sociologia Brasileira. In: SILVA, Josué Pereira da (Org.). Sociologia Crítica no Brasil. São Paulo: Annablume: 2012. p. 155-186.

ARANTES, Paulo Eduardo. Zero à Esquerda. São Paulo: Conrad, 2004.

. Sentimento da Dialética na Experiência Intelectual Brasileira. São Paulo: Paz e Terra, 1992. 1996.

. O Fio da Meada - sobre filosofia e vida nacional. São Paulo: Paz e Terra,

. Falsa consciência como força produtiva. Lua Nova, n. 19, novembro/1989, p.

ARRUDA, Maria Arminda do Nascimento. A embalagem do sistema: a publicidade no capitalismo brasileiro. São Paulo: Edusc, 2004.

. Trajetórias da sociologia da cultura no Brasil: os anos recentes. Revista USP, n. 50, 2001, p. 100-107.

CEVASCO, Maria Elisa e OHATA, Milton (Org.). Um crítico na periferia do capitalismo: reflexões sobre a obra de Roberto Schwarz. São Paulo: Companhia das Letras, 2007.

CHACON. Vamireh. História das Idéias Sociológicas no Brasil. São Paulo: USP/Grijalbo, 1977.

A recepção da Escola de Frankfurt no Brasil. Revista Brasileira de Filosofia.

Vol. XLI, Fac. 176, 1994, p. 453-457.

Em Debat: Rev. Dig., ISSNe 1980-3532, Florianópolis, n. 7, p. 126-149, jan-jul, 2012. 
. (Org.). Humanismo e Comunicação de Massa. Rio de Janeiro: tempo brasileiro, 1970.

. O Poço do Passado. Rio de Janeiro: Nova Fronteira, 1984.

COHN, Gabriel. A Sociologia e a Arte da Controvérsia. Revista Civilização Brasileira, n. 19, maio, 1968a, p. 229-250.

Petróleo e Nacionalismo. Corpo e Alma do Brasil. São Paulo: Difusão Européia do Livro, 1968 b.

Crítica e Resignação. Fundamentos da sociologia de Max Weber. São Paulo: T.A. Queiroz, 1978.

(Org.). Comunicação e indústria cultural. São Paulo: Companhia Editora Nacional/Edusp, 1971.

. Sociologia da Comunicação: Teoria e Ideologia. São Paulo: Pioneira, 1973. $18,1990$.

Difícil Reconciliação: Adorno e a Dialética da Cultura. Lua Nova. n. 20; p. 55-24, 1998.

Esclarecimento e Ofuscação: Adorno \& Horkheimer Hoje. Lua Nova. n. 43, p.

Entrevista. In: BASTOS, Élide Rugai et. al.. Conversas com Sociólogos Brasileiros. São Paulo: Ed. 34, 2006, p. 115-134.

COUTINHO, Carlos Nelson. A Escola de Frankfurt e a Cultura Brasileira. Revista Presença, n. 7, 1986, p. 100-112.

Cultura e sociedade no Brasil. Rio de Janeiro: DP \& A editora, 2005.

DIAS, Márcia Tosta. Sociologia da Comunicação no Brasil: apontamentos iniciais para uma necessária pauta de estudos. In: WAIZBORT, Leopoldo (Org.). A Ousadia Crítica: ensaios para Gabriel Cohn. São Paulo: Azougue, 2008, p. 89-98. 
DOMINGUES, José Maurício. Dominação e Indiferença na Teoria Crítica de Gabriel

Cohn. Teoria Crítica e (Semi) periferia. Belo Horizonte: Ed. UFMG, 2011.

DUARTE, Rodrigo. Sobre La Recepción de La Teoría Crítica en Brasil: El Caso

Merquior. Constelaciones - Revista de Teoria Crítica. n. 1, diciembre, 2009, p. 36-50.

FREITAG, Barbara. Habermas e a Editora Tempo Brasileiro ou a recepção de Habermas no Brasil. Revista Tempo Brasileiro, v. 111, 1992, p. 87-108.

. Habermas e a teoria do conhecimento como teoria social. Debate e Crítica, n. 4, Nov., 1974a, p. 61-82.

. A Sociologia Alemã Hoje. Debate e Crítica. São Paulo, nº 2, 4; jan./jun, $1974 b$.

HONNETH, Axel. The Critique of Power. Reflective Stages in a critical social Theory. London: The MIT Press, 1991.

HORKHEIMER, Max. Teoria Tradicional e Teoria Critica. São Paulo: Abril Cultural, 1983, p. 117-154.

JAY, Martin. La Imaginación Dialéctica. Madrid: Taurus, 1986.

KONDER, Leandro. Os Marxistas e a Arte. Rio de Janeiro: Civilização Brasileira, 1967.

KOTHE, Flávio. Benjamin \& Adorno: Confrontos. São Paulo: Ática, 1978.

. Para ler Benjamin. Rio de Janeiro. Francisco Alves, 1976.

MAAR, Wolfgang Leo. Notas sobre la Teoría Crítica em Brasil. Revista Internacional de Filosofia Política. Barcelona, n. 26. p. 45-51, 2005.

MERQUIOR, José Guilherme. Arte e Sociedade em Marcuse, Adorno e Benjamin. Rio de Janeiro: Tempo Brasileiro, 1969. 
. Razão do Poema. Rio de Janeiro: Civilização Brasileira, 1965.

. A Astúcia da Mímese. Ensaio sobre Lírica. Rio de Janeiro: Nova Fronteira, 1972.

. O Marxismo Ocidental. Rio de Janeiro: Nova Fronteira, 1987.

MICELI, Sérgio. A Noite da Madrinha. São Paulo: Perspectiva, 1972.

O chão e as nuvens: ensaios de Roberto Schwarz entre arte e ciência. In:

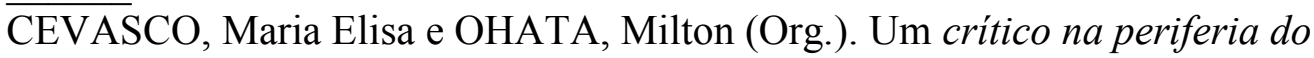
capitalismo: reflexões sobre a obra de Roberto Schwarz. São Paulo: Companhia das Letras, 2007.

MOTA, Carlos Guilherme. Ideologia da Cultura Brasileira (1933-1974). São Paulo: Ática, 1978.

ORTIZ, Renato. A Moderna Tradição Brasileira. São Paulo: Brasiliense, 1988.

PRESSLER, Günter Karl. Benjamin, Brasil: a recepção de Walter Benjamin, de 1960 a 2005 - um estudo sobre a formação da intelectualidade brasileira. São Paulo:

Annablume, 2006.

RIDENTI, Marcelo. Em busca do povo brasileiro: artistas da revolução, do CPC à era da $T V$. Rio de Janeiro: Record, 2000.

ROUANET, Sérgio Paulo. De Eros a Sísifo. Revista Tempo Brasileiro, n. 17/18, 1968.

SCHWARZ, Roberto. Ao Vencedor as Batatas. São Paulo: Ed. 34, 2000.

. Um Mestre na Periferia do Capitalismo. São Paulo: Ed. 34, 2001.

. O pai de família e outros estudos. Rio de Janeiro: Paz e Terra, 1978.

. A sereia e o desconfiado. Rio de Janeiro: Civilização Brasileira, 1965. 
Que Horas são? São Paulo: Companhia das Letras, 2006.

. Um seminário sobre Marx. Novos Estudos Cebrap, n. 50, março, 1998, p. 99113.

. Seqüencias Brasileiras. São Paulo: Companhia das Letras, 1999.

. Martinha versus Lucrécia. São Paulo: Companhia das Letras, 2012.

SILVA, Josué Pereira da. Teoria Crítica e sua recepção no Brasil. Idéias. Vol. 14, 2007, p. 137-147.

SOARES, Jorge Coelho. A recepção das ideias de Marcuse no Brasil. disponível em: http://www.uta.edu/huma/illuminations/marc1.htm; acesso em: 25 set 2010.

. Marcuse no Brasil. Londrina: Cefil, 1999.

VLLAS BÔAS, Gláucia. A Recepção da Sociologia Alemã no Brasil. Rio de Janeiro: Topbooks, 2006.

WAIZBORT, Leopoldo (Org.). A Ousadia Crítica: ensaios para Gabriel Cohn. São Paulo: Azougue, 2008. 